\title{
Biogeocenosis development during initial revegetation of a coal combustion ash dump
}

\author{
Natalia Sheremet ${ }^{1, *}$, Ivan Belanov ${ }^{2}$, Vladimir Doronkin ${ }^{1}$, Tatiana Lamanova ${ }^{1}$, and Natalia \\ Naumova $^{2}$ \\ ${ }^{1}$ Central Siberian Botanical Garden, SB RAS, 630090 Novosibirsk. Russia \\ ${ }^{2}$ Institute of Soil Science and Agrochemistry, SB RAS 630090, Novosibirsk, Russia
}

\begin{abstract}
The initial stage of biogeocenoses development on the coal ash dump produced by the thermal power staton in Novosibirsk (55.000, 83.068), Russia, were studied after 9 years of spontaneous revegetation. Soil properties, soil cover and plant communities were examined in detail. The predominating types of embryozems and transition from open to succession plant communities were described. Soil substrate moisture content was found to determine changes in plant species composition, projective cover and abundance, altogether causing asynchronicity of soil formation in different sites.
\end{abstract}

\section{Introduction}

Several major power plants operate in Novosibirsk, combusting coal to produce electric power and heat for the city. Of these plants Central thermal power station-5 (CTPS-5) is the biggest in the city and one of the biggest in the Asian part of Russia, accounting for $50 \%$ of electric power production in the Novosibirsk region.

According to the technological process, the coal combustion wastes (fly ash, an oxidised, non-combustible material of very fine size and grayish in colour) are fluidized and transported into ash dumps. After the dumps are filled to their projected capacity, they require certain recultivation for the occupied territories to be safely used. Such technogenic dumps can be sources of adverse effect $[1,2]$ on the ground water and air quality due to diffusion of chemical compounds and ash spreading by wind erosion, respectively. Thus assessment of ecological status and determination of the rate of soil and vegetation natural restoration are quite urgent for understanding the ways to decrease adverse environmental impacts [3].

Ash dump 1 from the CTPS-5 is located upwards in Baryshevsky ravine near the watershed between the Inya and Plyushikha Rivers (55.000, 83.068). The dump was started in 1987, filled to the projected capacity in 2008 when the transportation of the fluidized ash was stopped. The dump of the total area of 41.1 ha consists of two areas divided by a dam. In 2010-2011 one area was subjected to technical recultivation by overlaying the ash with a layer of potentially fertile substrate of varying thickness. The other part of 17.7 ha was not overlaid and left for natural revegetation.

\footnotetext{
* Corresponding author: nsheremet@yandex.ru
} 
The aim of the work was to characterize in detail soils and phytocenoses development during the initial stages of revegetation of the coal ash dump of the CTPS-5 in Novosibirsk.

\section{Materials and methods}

\subsection{Location of the study sites}

The study area is located 55.000, 83.068. The study was carried out on three coal ash dump sites during the $9^{\text {th }}$ year under natural revegetation. The sites were adjacent to each other. The area of the studied sites was 4 ha for Site-1, 6.2 ha for Site- 2 and 5 ha for Site- 3 . According to the regional agroclimatic zoning, the Novosibirsk region falls within the forest-steppe zone of the Northern Cis-Altai province. The climate of the region is characterized with the sum of above $+10^{\circ} \mathrm{C}$ air temperatures of $1926^{\circ} \mathrm{C} \cdot$ day, yearly precipitation of $300-400 \mathrm{~mm}, 119$ days of frost-free period and the average daytime temperature of July (the hottest month) of $25.7^{\circ} \mathrm{C}$.

The studied revegetating coal ash dump sites are adjacent to the small areas covered by birch (Betula pendula Roth.) forest with goutweed and grasses as surface cover and the underbrush of Sorbus sibirica Hedl., Viburnum opulus L. Crataegus sanguinea Pall. and Pinus sylvestris L.

Since the study sites had not been recultivated, the plants disseminated on the pure mineral substrate, i.e. coal ash, thus the revegetation successions can be considered as primary. Coal ash is a specific mineral substrate, impeding plant growth due to high $\mathrm{pH}$ and the absence of nitrogen.

Soil and plant sampled were collected in July and August 2017.

Soils were described according to the soil substrate genesis classification of technogenic landscapes [4] as embryozems or, according to WRB, as technosols [5]. Zonal soil types in the forest-steppe of the region are grey wooded soils, or Haplic Luvisols [5].

According to the Russian classification, the main technosol types at the initial stages of soil formation are called embryozems, which can be grouped in the following main types: initial embryozem (Ei), organic matter accumulating embryozem (Eo), soddy embryozem (Es) and humus accumulating embryozem (Eh). Embryozem development goes from EiEo-Es-Eh syngenetically with plant succession stages [6].

At each study site a pit was dug, and 3 subcores were taken from nascent genetic horizons, bulked together to comprise one composite sample. Field-moist soil samples were $2-\mathrm{mm}$ sieved and stored in a refrigerator $\left(+4{ }^{\circ} \mathrm{C}\right)$ prior to analyses. The content of soil organic (SOC) and soil inorganic carbon (SIC) was determined by stepwise loss on ignition method [7] using 2-4 g soil aliquots. Soil total nitrogen (STN) was determined by PerkinElmer elemental analyzer. Available forms of macronutients $\left(\mathrm{NO}_{3}^{-}, \mathrm{NH}_{4}{ }^{+}, \mathrm{P}_{2} \mathrm{O}_{5}\right)$ were determined in field-moist samples by standard techniques: briefly, nitrate was determined potentiometrically in $0.03 \mathrm{M} \mathrm{K}_{2} \mathrm{SO}_{4}$ extracts, while ammonium was measured colorimetrically in $2 \mathrm{~N} \mathrm{KCl}$ extracts, and available $\mathrm{P}$ was extracted with $0.5 \mathrm{M} \mathrm{NaHCO}_{3}$ solution and determined colorimetrically [8]. Soil $\mathrm{pH}$ was measured in a supernatant of soil-water solution (1:5 v/v). Exchangeable $\mathrm{K}^{+}, \mathrm{Na}^{+}, \mathrm{Ca}^{2+}$ and $\mathrm{Mg}^{2+}$ were determined by atomic adsorption in ammonium citrate extracts. Granulometric composition of soil substrate was determined according to [9]. Total dissolved solids in soil water extracts were measured potentiometrically. The rate of carbon dioxide release by soil substrates, i.e. soil respiration, was measured in laboratory with $\mathrm{CO}_{2}$ data loggers.

To study the floristic composition of plant communities plant samples for herbarium were collected and geobotanical descriptions made in each key study site during the growing season. To determine the above-ground phytomass standing stock and species 
contribution into it the aboveground plant material was clipped by species in 4 replicates, air-dried and weighted.

Soil properties were analyzed by principal component analysis with Statistica v.6.1 software.

\section{Results}

\subsection{Site-1}

Revegetation and soil development on Site 1 resulted in $80 \%$ of the area occupied by Ei and $20 \%$ occupied by Eo. Since Ei in their physical and chemical properties are very similar to the original ash substrate, substantial contribution of Ei areas into soil cover can be assessed as edaphically not favourable environment for phytocenosis development. Granulometrically both Ei and Eo soils were light loams with alkaline $\mathrm{pH}$ (8.02-8.83). The 0-20 cm soil layer had low field water content (8.3-10.5\%) when sampled. The $\mathrm{C}_{1}$ horizon had soil dry mass density of $1.3 \mathrm{~g} / \mathrm{cm}^{3}$, while $C_{2}$ horizon had $0.9 \mathrm{~g} / \mathrm{cm}^{3}$. Total porosity among structural aggregates accounted for $49.2-63.8 \%$. Mass density of the solid matter on this site was the highest, reaching $2.6 \mathrm{~g} / \mathrm{cm}^{3}$, whereas organic matter content in the rootpenetrated layer was the lowest among the studied embryozems ( $c a .1 .5 \%)$.

The 9 years of Site-1 natural revegetation resulted in the open herbaceous and smallreed assemblage, accompanied by Hippophä̈ rhamnoides L. and with Calamagrostis epigeios (L.) Roth. predominating. The total projective cover was 5\%. Higher vascular plants were represented by 18 species. The vegetation consisted of singular plants, growing on the smaller part of the Site-1 area. The grass stand was on average $40 \mathrm{~cm}$ high. The herb assemblage was dominated by sages Artemisia integrifolia L. and A. vulgaris L., tower rockcress (Turritis glabra L.). The legumes were dominated by white sweet clover (Melilotus albus Medic.). Woody plants were represented by the buckthorn Hippophaë rhamnoides L. pyramid poplar Populus italica (Du Roi) Moench underbrush. Bryophytes also made important contribution into the site plant assemblage with their projective cover of $70-80 \%$ and 4 species, among which Leptobryum pyriforme (Hedw.) Wits. and Bryum sp. predominated.

The standing aboveground living phytomass was estimated to reach $109 \mathrm{~kg} / \mathrm{ha}$, while standing dead phytomass was $9 \mathrm{~kg} / \mathrm{ha}$.

\subsection{Site-2}

On this site Ei soil first transformed into Eo and then further into Es due to the plant community development from the open to the closed one, dominated by grasses. Revegetation and soil development on this site resulted in $75 \%$ of the area occupied by Es and $25 \%$ occupied by fragmented Eo. Soil environment is quite favourable for plant growth and development. Granulometrically both Es and Eo soils were medium loams with alkaline $\mathrm{pH}$ (8.08-8.65). Soil substrate moisture content is an important factor, determining plant community structure on revegetation coal ash dumps. As compared with Site-1, Site-2 soil substrates contained more water (27-32\%). The $\mathrm{A}_{1}-\mathrm{C}_{1}$ horizons were more loose and less dense $\left(0.4-0.7 \mathrm{~g} / \mathrm{cm}^{3}\right)$, with $\mathrm{C}_{2}$ horizon being slightly more dense $\left(0.9 \mathrm{~g} / \mathrm{cm}^{3}\right)$. Total porosity among structural aggregates changed from 80 to $60 \%$ with soil depth. Mass density of solids on this site was $2.2 \mathrm{~g} / \mathrm{cm}^{3}$, whereas organic matter content in the rootpenetrated layer was the highest among the studied embryozems, ranging $2.2-3.7 \%$.

The clover and smallreed phytocenosis had formed on Site- 2 over the 9 years of natural revegetation. The aboveground phytomass stand was rather dense with an average height of 
$90 \mathrm{~cm}$ and $90-100 \%$ of the total projective cover. The main gramineous and leguminous edificator plants were represented by Calamagrostis epigeios and Melilotus albus, respectively. Relatively even distribution of $C$. epigeios throughout Site-2 area resulted from its biology, i.e. was due to the species ability to disseminate rapidly via rhizomes. High abundance of white sweet clover plants, observed on Site-2, was observed earlier on Verhny Taguil coal ash dump in the Urals region [10]. In contrast to evenly distributed smallreed plants, the clover plants had patchy distribution, resulting in mosaic vegetation. The plant community was found to consist of 14 higher vascular plant species and 3 pryophyte (Barbula unguiculata Hedw., Bryum cf. caespiticium Hedw., Ditrichum pusillum (Hedw.) Hampe).

The standing aboveground living phytomass was estimated as $4961 \mathrm{~kg} / \mathrm{ha}$, while standing dead phytomass was $1154 \mathrm{~kg} / \mathrm{ha}$.

\subsection{Site-3}

The soil cover of the site was equally comprised by Eo and Es. Granulometrically both Eo and Es embryozems were medium loams with alkaline $\mathrm{pH}(8.23-8.93)$. The $0-20 \mathrm{~cm}$ soil layer had low field water content $(8.3-10.5 \%)$ when sampled. The $\mathrm{C}_{1}$ horizon had specific mass of $1.3 \mathrm{~g} / \mathrm{cm}^{3}$, while $C_{2}$ horizon had $0.9 \mathrm{~g} / \mathrm{cm}^{3}$. As compared with Site-1 and Site-2, Site-3 soil substrates contained excessive water (more than $39 \%$ in $0-20 \mathrm{~cm}$ layer). Similarly to Site-2, the $A_{1}-C_{1}$ horizons were more loose and less dense $\left(0.4-0.7 \mathrm{~g} / \mathrm{cm}^{3}\right)$, with $\mathrm{C}_{2}$ horizon being slightly more dense $\left(0.9 \mathrm{~g} / \mathrm{cm}^{3}\right)$. Total porosity among structural aggregates changed from 60 to $45 \%$ with soil depth. Mass density of solids in Site- 3 soil substrate was $2.1 \mathrm{~g} / \mathrm{cm}^{3}$, whereas organic matter content in the root-penetrated layer was the highest among the studied embryozems, ranging $1.2-2.4 \%$.

Due to higher soil substrate water content on Site-3 there grew such hydrophytes as the graceful cattail Typha laxmannii Lepech. and the common reed Phragmites australis (Cav.) Trin. ex Steud. The Site-3 area is intermittently flooded. The phytomass stand was on average $80 \mathrm{~cm}$ high, forming $40-50 \%$ of total projective coverage. The phytocenosis could be described as the smallreed-bentgrass one. Similar to Site-2, the main edificator was Calamagrostis epigeios, with its bunch stabilizing ash substrate and hence decreasing dust spreading by wind. The dominating redtop bentgrass Agrostis gigantea Roth. was spread unevenly throughout the Site-3 area. Grasses dominated the site plant community composition. Woody plants were represented by two willow species (Salix caprea L., $S$. viminalis $\mathrm{L}$.), their trees reaching as high as $2 \mathrm{~m}$ sometimes.

The standing aboveground living phytomass was estimated as $2373 \mathrm{~kg} / \mathrm{ha}$, while standing dead phytomass was $1673 \mathrm{~kg} / \mathrm{ha}$.

\subsection{Principal component analysis}

Principal component analysis of the data matrix with soil properties as variables and different study sites as objects showed quite distinct location of the studied sites in the plane of PC1 and PC2 (Fig.1), together accounting for more than $2 / 3$ of the soil data variance.

The humus horizon of the undisturbed Luvisol under birch forest, as expected, lies far apart from the technosols due to organic $\mathrm{C}$, total and total contents, as shown by the location of soil properties in the plane of PC1 and PC2 (Fig.2) As PC1 can be interpreted as related to soil substrate physical properties mostly, while PC2 is related to organic matter quantity and quality. Soil respiration rate also contributed to PC1, being higher in Site-2 and Site-3 soil substrates due to increased fresh organic carbon input with increased phytomass production and higher water content. 


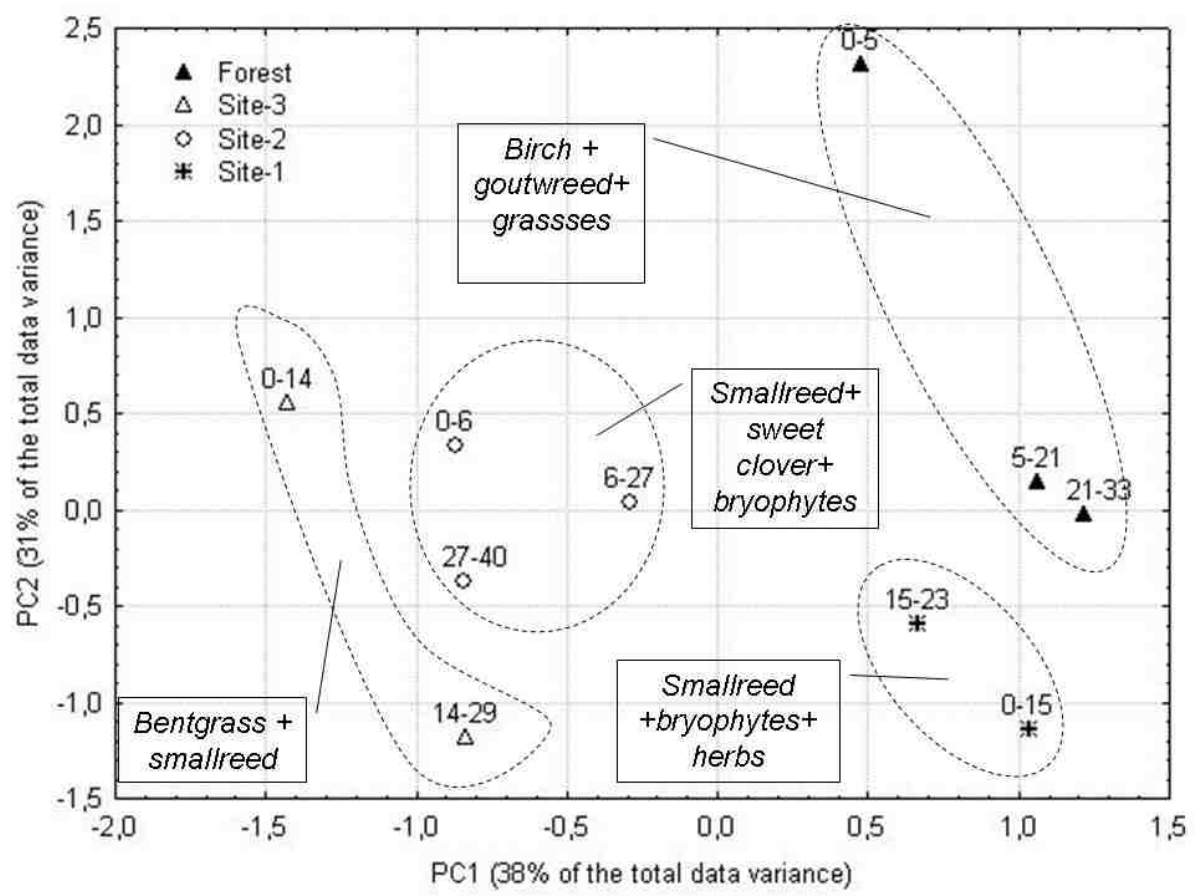

Fig.1. Location of soil samples in the plane of the first two principal components. Forest undisturbed birch forest on Haplic Luvisol; Site-1, Site-2 and Site-3 - sites on the coal ash dump under natural revegetation for 9 years on Technosols. Numbers above markers indicate soil substrate sampling depth in $\mathrm{cm}$. Text in rectangles describes plant dominants.

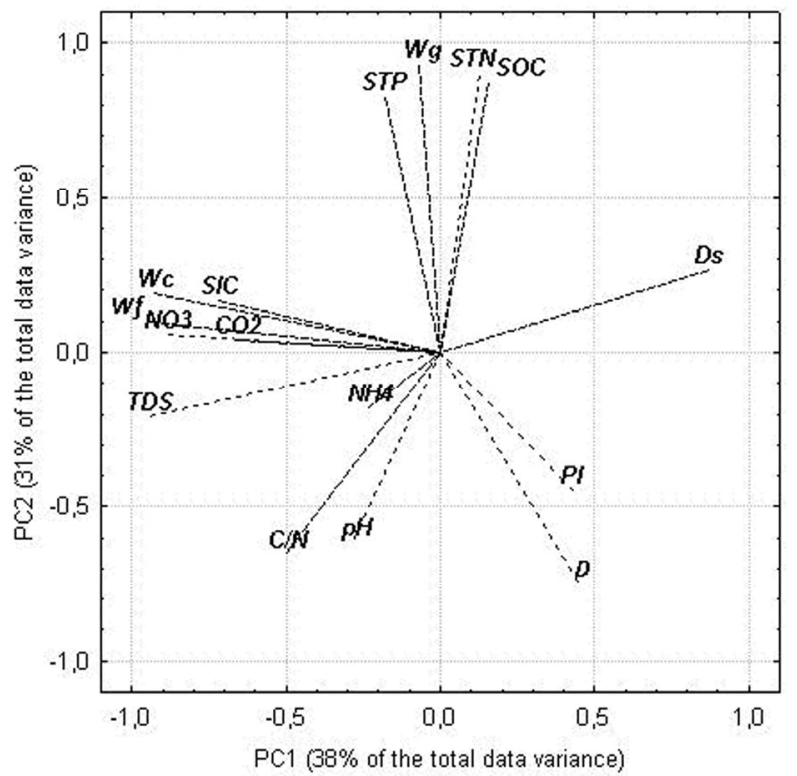

Fig.2. Location of soil substrate properties in the plane of the first two principal components. Abbreviations: STP - soil total phosphorus, STN - soil total nitrogen, SOC - soil organic carbon, $\mathrm{CO}_{2}$ - soil respiration, SIC - soil inorganic carbon, TDS - total dissolved solids, Wc, Wg, Wf capillary, hygroscopic and field water contents, resp., D-soil density, Ds - density of solids, Pl labile phosphorus content. 


\section{Conclusion}

The results showed that on all studied sites of the coal ash dump 9 years of natural revegetation of the ash substrate led to the phytocenoses, dominated by perennial herbs and grasses ( 25 species) and scarce woody plants (4 species). Bryophytes were represented by 7 species. Increasing water in the topsoil substrate resulted in shifts in vegetation and soil cover from the open plant community on the initial embryozem to grasses and legumes community on the organic matter accumulating embryozems and further on towards the grasses community on the organic matter accumulating and soddy embryozems. On the two study sites environment favoured phytomass production and biological turnover in general and, consequently, soil development, resulting after nine years in less than $5 \%$ of soil cover occupied by initial embryozem. Changes in water content of the coal ash substrate brought shifts in plant species composition, projective cover, plant abundance and phytomass production, altogether leading to asynchronicity of site-specific soil formation stages. Thus despite the apparent monotony of the coal ash dump (horizontally even surface, homogenous substrate with the same properties at the start of revegetation) different ecotopes developed due to specific environmental conditions, such as microrelief, local water input and retention. The ecotope diversity determined vegetation diversity and phytomass production and hence soil formation differentiation. Overall it can be concluded that natural revegetation of coal ash dumps leads to productive plant communities under sufficient water supply.

The study was financially supported by Grant from the Russian Fund of Fundamental Research (№ 18-44-540002 p_a). Bryophyte species were determined by Doctor of Biological Sciences O. Yu. Pisarenko from the Central Siberian Botanical Garden of the SB RAS, 630090, Novosibirsk, Russia

\section{References}

1. R.J. Haynes, J. Environ. Manage. 90:1, 43 (2009)

2. S.Y. Pan, H. Morrison, L.Gibbons, J.Zhou, S.W.Wen, M.Desmeules, Y.Mao, J. Occup. Environ. Med. 53:5, 522 (2011)

3. D.Maiti, B. Prasad, Appl. Ecol. Env. Res. 14:2, 185-212 (2016)

4. V.M. Kurachev, V.A. Androkhanov. Contemporary Problems of Ecology. 3 (2002). In Russian

5. IUSS Working Group, WRB, World Reference Base for Soil Resources 2006. International soil classification system for naming soils and creating legends for soil maps ( FAO, Rome, 2006)

6. V.A.Androkhanov, V.M.Kurachev, E.D.Kulyapina, Soils of technogenic landscapes: genesis and evolution, (SB RAS Pubs., Novosibirsk, 2004) in Russian

7. Q. Wang, Y.Li, Y. Wang, Environ. Monit. Assess. 174, 241-257 (2011)

8. W.H.Hendershot, H. Lalande, M.Duquette, Soil Sampling and methods of Analysis (CRC Press, Boca Raton, 2008)

9. D.Kroetsch, C.Wang, Soil Sampling and methods of Analysis. (CRC Press, Boca Raton, 2008)

10. A.K. Makhnev, T.S. Chibrik, M.R. Trubina, N.V. Lukina, N.E. Gebel, A.A. Terin, Yu.I. Elovikov, N.V. Toporkov, Ecological basis and methods for biological recultivation of coal ash from power heating stations in the Ural region (Ekaterinburg, 2002) in Russian 